\title{
Ecological Upgrade of Normal-Strength Mortars by Using High Volume of GGBS
}

\author{
Peiyuan Chen $\mathbb{D}^{1},{ }^{1,2}$ Shicheng He, ${ }^{1}$ Pengju Wang, ${ }^{1}$ Ying Xu, ${ }^{1}$ Xiuping Hu, ${ }^{1}$ and Qian Chen ${ }^{1}$ \\ ${ }^{1}$ School of Civil Engineering and Architecture, Anhui University of Science and Technology, Huainan 232001, China \\ ${ }^{2}$ Hefei Construction Engineering Group Co., Ltd., Hefei 230088, China \\ Correspondence should be addressed to Peiyuan Chen; peiyuan29@126.com
}

Received 10 December 2019; Revised 20 May 2020; Accepted 3 June 2020; Published 22 June 2020

Academic Editor: Wayne Yu Wang

Copyright ( $\odot 2020$ Peiyuan Chen et al. This is an open access article distributed under the Creative Commons Attribution License, which permits unrestricted use, distribution, and reproduction in any medium, provided the original work is properly cited.

Normal-strength concrete is widely used in construction sites considering the cost, technology, and structural safety. The ecological upgrade of such materials is more meaningful for the sustainable development in a greener way. To this end, the feasibility of ecological upgrade of normal-strength mortars (NSM) by using high volume of ground granulated blast furnace slag (GGBS) (70\%-90\%) was evaluated in this paper. Comprehensive experiments were conducted to investigate the influences of experimental variables such as content of cement, curing temperature, and mass ratio of water to binder $(w / b)$ on the fresh properties, compressive strength, hydration products, microstructure, and pore structure of NSM. Ecoefficiency evaluation was conducted based on the energy requirement for the whole production of cement and GGBS. Experimental results showed that ecological upgrade of NSM was viable and feasible. When substituting $70 \%$ to $90 \%$ cement by GGBS, the energy requirement of $1 \mathrm{t}$ binder can be accordingly saved by $67 \%$ to $86 \%$, and the performance energy can be reduced from 25.4 (kWh/t)/MPa to 6 to 8 $(\mathrm{kWh} / \mathrm{t}) / \mathrm{MPa}$. With proper contents of GGBS (70\% or $75 \%)$, the $28 \mathrm{~d}$ compressive strengths were acceptable with reductions less than $10 \%$. Evaluated curing temperatures and decreased $w / b$ were viable methods to promote the early-age compressive strength of NSM incorporating high volume of GGBS. For instance, raising the curing temperature to $40^{\circ} \mathrm{C}$ can help achieve higher earlyage compressive strength than that of the control group. In addition, the pore sizes within ZII $(<100 \mathrm{~nm})$ of GGBS-incorporated NSM were refined by over $20 \mathrm{~nm}$.

\section{Introduction}

Nowadays, the requirements of low carbon and environmental protection on the construction industry have prompted great motivations to seek alternative materials to cement since the emission of about $7 \%$ global $\mathrm{CO}_{2}$, the consumption of $5 \%$ global primary industrial energy, and the release of large amounts of $\mathrm{NO}_{x}, \mathrm{SO}_{2}$, particulate matter, mercury, and other compounds attributed to the cement production [1-3]. One of the promising strategies is the substitution of cement by low-carbon pozzolanic mineral admixtures, i.e., ground granulated blast furnace slag (GGBS) [4], a by-product from blast furnaces during the production of pig iron $[5,6]$. GGBS containing calcium silicoaluminate as its major component is highly vitreous in phases and is reactive to hydroxides released from the cement self-hydration to yield hydration products, i.e., CSH gel and hydrocalcium aluminate $[7,8]$.

The employment of GGBS in cementitious materials brings two conspicuous benefits. The first one is the direct environment effect in terms of energy saving, pollutant discharge reduction, natural resources protection, and waste recycling. The manufacture of GGBS mainly involves the processes of cooling of molten slag through high-pressure water jets, drying, and grinding in a rotating ball mill $[5,9]$. These operations consume less energy as compared to the clinkering process of cement manufacturing [10]. Shi and Qian [11] estimated that the required energy for grinding GGBS was less than $10 \%$ of the total energy requirement for producing cement. Prominently, greenhouse emission and waste or toxic matters release related to the cement production are reduced $[12,13]$. It was reported that the 
incorporation of $50 \%$ GGBS in mortar or concrete can help reduce about $0.5 \mathrm{t} \mathrm{CO}_{2}$ emission [10].

The second benefit can be classified into the material effect. It is generally agreed that cementitious materials blended with GGBS develop refined pore sizes in their service life $[14,15]$. Li et al. [16] confirmed that the pore sizes of paste or mortar moved from RII size range $(10 \mathrm{~nm}-100 \mathrm{~nm})$ to RI size range $(<10 \mathrm{~nm})$ when $70 \%$ GGBS was incorporated. This finer pore structure of GGBScontaining cementitious composites contributes to barriers for the ingression of harmful substance, i.e., chloride ion and sulfate $[5,15]$. Furthermore, GGBS contains no $\mathrm{C}_{3} \mathrm{~A}$, making GGBS-incorporating cementitious composites less reactive to sulfates [5]. GGBS itself or its crystalline phases provides additional nucleation sites for the hydration products of cement, contributing to accelerated hydration of cement $[17,18]$. Other reported benefits cover the fire resistance, improved workability, increased pumpability, densified ITZ microstructure, and low hydration heat [19-22].

This is attractive in construction sites with dominating requirements of normal-strength concrete (NSC), which receives less attention in the recent years in the concrete studies compared to (ultra) high-strength concrete. Actually, NSC is widely used in construction sites considering the cost, technology, and structural safety. The ecological upgrade of NSC by incorporating high volume of GGBS may provide a better opportunity to develop in a more environmentally friendly manner. To achieve a maximized environmental or material benefit, the substitution rates of GGBS for cement are thus pivotal. By now, the replacement quantity of GGBS to cement has been investigated from $30 \%$ to $85 \%$ by weight; however, $50 \%$ is a common value in most applications [5, 7, 9, 23, 24]. Although abundant studies regarding the properties of concrete or mortar incorporating GGBS up to $60 \%$ of the total binder have been carried out, there are still lack of sufficient concerns on higher substitution rates larger than $60 \%$ [14]. This may be mainly because incorporating high volume of GGBS into cementitious composites brings about low early-age strength $[25,26]$. Nowadays, the defect of low early-age strength can be overcome by means of elevated curing temperatures $[27,28]$, increasing GGBS fineness [24, 29], and using finer mineral admixtures, i.e., nano-silica [20, 30], nano- $\mathrm{CaCO}_{3}[31]$, silica fume [32], and metakaolin [33]. In addition, it is also largely agreed that, with proper proportion, GGBS-incorporating cementitious composites can develop comparable or superior compressive strength than that incorporating cement only at late ages.

Therefore, this paper intends to ecologically upgrade normal-strength mortars (NSM) by incorporating high volume of GGBS. The investigated substitution ratios of cement by GGBS range from $70 \%-90 \%$ with an interval of $5 \%$. The feasibility of mechanical compensation methods that higher curing temperatures or lower $w / b$ will be examined. Comprehensive experiments were conducted to investigate the content of cement, curing temperature, and $w / b$ on the fresh properties, compressive strength, hydration products, microstructure, and pore structure of NSM. TGA-
DTG, SEM, XRD, and MIP were applied to study the underlying mechanisms on multiscales. The ecoefficiency of NSM incorporating various volume of GGBS was evaluated based on the energy requirement for the whole production of cement and GGBS.

\section{Materials and Methods}

2.1. Materials. P.O. 42.5 ordinary Portland cement was purchased from Anhui Conch Cement Co., Ltd., China. GGBS corresponding to Grade S105 was used according to JC/T2238 [34]. The apparent density and chemical composition of cement and GGBS are listed in Table 1. Their particle size distributions are presented in Figure 1. It can be found that GGBS is finer in particle sizes as the mean particle sizes of cement and GGBS are $28.19 \mu \mathrm{m}$ and $16.18 \mu \mathrm{m}$, respectively. Sand was ordinary river sand with a finesse of 2.6 and an apparent density of $2550 \mathrm{~kg} / \mathrm{m}^{3}$. Water used throughout this study was city tap water.

The applied characterization analysis for cement and GGBS was performed by a XRF-1800 sequential X-ray fluorescence spectroscopy (XRF) for the chemical composition investigation and an ASALD-7101 laser particle size analyzer (LPSA) for the particle size analysis.

2.2. Mixing Proportions. Ten mixtures containing one control group were designed, as presented in Table 2. The $28 \mathrm{~d}$ compressive strength of the control group was 42.9 $\mathrm{MPa}$, belonging to the context of NSM that normally less than $60 \mathrm{MPa}$. Three variables were considered encompassing (1) contents of cement in the blend binders $(0 \%$, $10 \%, 15 \%, 20 \%, 25 \%$, and $30 \%$ ), (2) curing temperatures $\left(23^{\circ} \mathrm{C}, 40^{\circ} \mathrm{C}\right.$, and $\left.60^{\circ} \mathrm{C}\right)$, and $(3) \mathrm{w} / \mathrm{b}(0.35,0.45$, and 0.55$)$. All mixtures were prepared following the same procedure. Cement and/or GGBS and sand were mixed firstly and stirred by a harbor mixer in low speeds for $5 \mathrm{~min}$. Then, water was added, and the mixture was stirred for another $3 \mathrm{~min}$. Fresh mixture was casted into $50 \mathrm{~mm}$ cubic mortar for the compressive strength testing. Mortars were firstly sealed and cured in specified environments within modules for $24 \mathrm{~h}$, as indicated in Table 2. Afterwards, they were demoulded and continuously cured in previous curing environment. Average value of mortar was reported by quadruplicate specimens. Mixtures were coded in the formula of $C_{x x} T_{y y} W_{z z}$ to directly indicate the content of cement in the blend binder, curing temperature, and $w / b$ in sequence.

\subsection{Test Methods}

2.3.1. Setting Time and Density Tests. The densities of fresh mixtures were simply measured by a container with fixed volume. Setting times of fresh pastes were tested by using a Vicat needle according to ASTM C191 [35].

2.3.2. Hydration Products Analysis. Paste samples were soaked in isopropanol to stop the hydration process. They were vacuum-dried and grounded into particle sizes less 
TABLe 1: Apparent density and chemical composition of cement and GGBS.

\begin{tabular}{lccccccc}
\hline \multicolumn{2}{c}{\begin{tabular}{c} 
Apparent density \\
\multicolumn{2}{c}{$\left(\mathrm{kg} / \mathrm{m}^{3}\right)$}
\end{tabular}} & $\mathrm{CaO}$ & $\mathrm{SiO}_{2}$ & $\mathrm{Al}_{2} \mathrm{O}_{3}$ & $\mathrm{MgO}$ & $\mathrm{Fe}_{2} \mathrm{O}_{3}$ & $\mathrm{TiO}_{2}$ \\
\hline Cement & 3100 & 71.3 & 13.7 & 5.3 & 0.4 & 6.0 & 0.5 \\
GGBS & 2800 & 43.7 & 26.5 & 18.2 & 4.9 & 1.0 & 0.9 \\
\hline
\end{tabular}

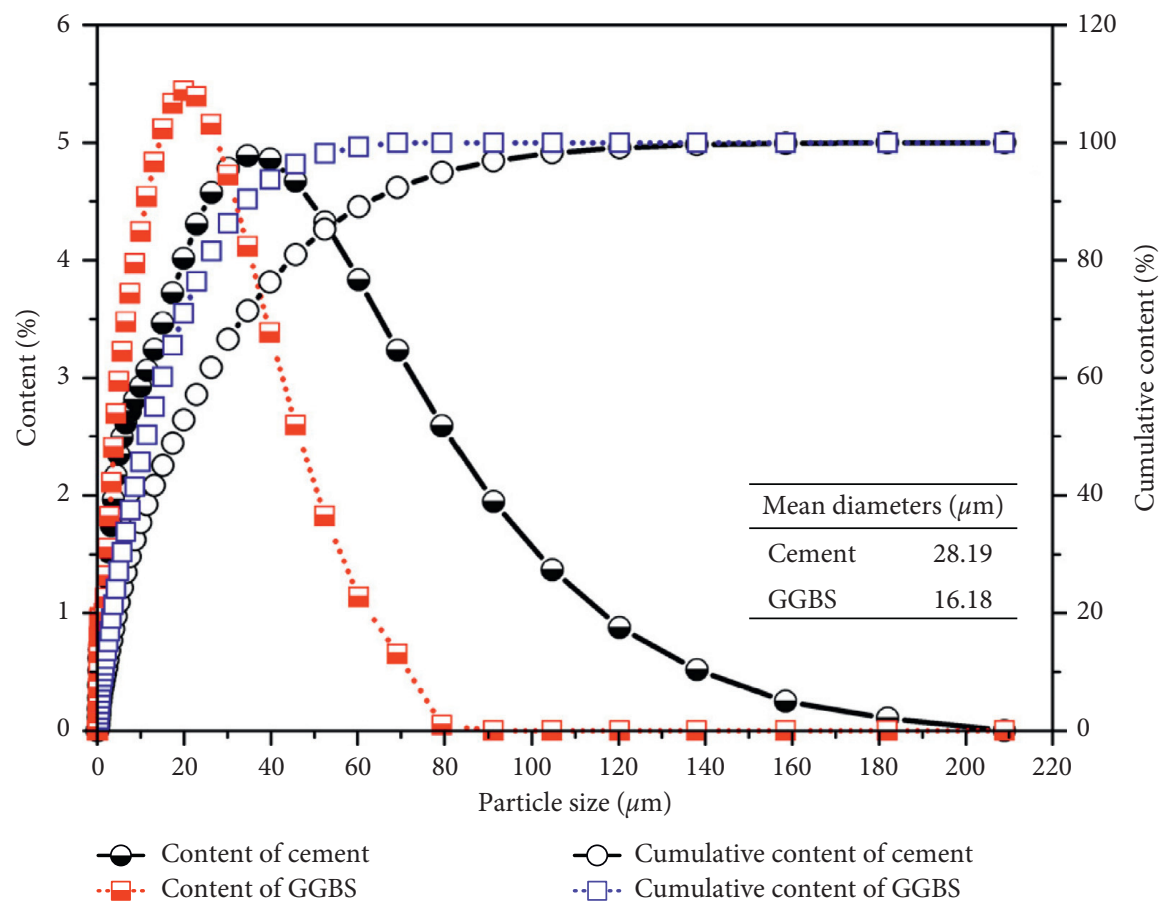

Figure 1: Particle size distributions of cement and GGBS.

TABLE 2: Mixing proportions.

\begin{tabular}{|c|c|c|c|c|c|c|}
\hline Groups & Curing conditions & $w / b$ & GGBS & Cement & Water & Sand \\
\hline Con & & & 0 & 41.40 & 18.60 & 40.00 \\
\hline C20T23W45 & & & 8.28 & 33.12 & 18.60 & 40.00 \\
\hline C10T23W45 & $23 \pm 2^{\circ} \mathrm{C}$ & & 4.14 & 37.26 & 18.60 & 40.00 \\
\hline C15T23W45 & $>95 \% \mathrm{RH}$ & & 6.21 & 35.19 & 18.60 & 40.00 \\
\hline C25T23W45 & & & 10.35 & 31.05 & 18.60 & 40.00 \\
\hline C30T23W45 & & 0.45 & 12.42 & 28.98 & 18.60 & 40.00 \\
\hline C20T40W45 & $\begin{array}{c}40 \pm 2^{\circ} \mathrm{C} \\
>95 \% \mathrm{RH}\end{array}$ & & 8.28 & 33.12 & 18.60 & 40.00 \\
\hline C20T60W45 & $\begin{array}{c}60 \pm 2^{\circ} \mathrm{C} \\
>95 \% \mathrm{RH}\end{array}$ & & 8.28 & 33.12 & 18.60 & 40.00 \\
\hline C20T23W35 & $23 \pm 2^{\circ} \mathrm{C}$ & 0.35 & 8.89 & 35.55 & 15.55 & 40.00 \\
\hline C20T23W55 & $>95 \% \mathrm{RH}$ & 0.45 & 7.74 & 30.97 & 21.29 & 40.00 \\
\hline
\end{tabular}

than $74 \mu \mathrm{m}$ for further study. A TTR-III h/h rotating anode $\mathrm{X}$-ray diffractometer (XRD) with $\mathrm{Cu}-\mathrm{Ka}$ radiation at $40 \mathrm{kV}$ and $200 \mathrm{~mA}$ was applied to study the crystal compositions. The scan speed and scope of each sample was $8 \% \mathrm{~min}$ and $2 \theta=10^{\circ}-60^{\circ}$, respectively. A TGA/DSC $1 / 1600$ high-temperature thermogravimetric analyzer was also applied to further study the quantitative composition of the hydration products of each sample. The grounded pastes were heated from $50^{\circ} \mathrm{C}$ to $800^{\circ} \mathrm{C}$ with the speed of $10^{\circ} \mathrm{C} / \mathrm{min}$.

2.3.3. Microstructure and Pore Structure Analysis. Microstructure analysis of $28 \mathrm{~d}$ mortars was performed by a FlexSEM1000 scanning electron microscope (SEM). SEM 
samples were collected from the compressive strength testing and were stored in isopropanol to cease the hydration process. Prior to SEM observation, vacuum drying was applied on these samples. A layer of palladium particles was sprayed on the fresh fracture surface for $120 \mathrm{~s}$ in the frontage and $30 \mathrm{~s}$ in the side direction to achieve well electroconductibility. The pore structure of $28 \mathrm{~d}$ mortars was studied by an AutoPoreIv 9510 mercury intrusion porosimetry (MIP).

2.4. Ecoefficiency Evaluation. Ecoefficiency evaluation was carried out for a full-life cycle environmental assessment of the proposed technology. The ecoefficiency of the blend cement was evaluated by simply calculating the energy required for cement manufacture based on the energy requirement for the whole production of cement and GGBS, as proposed by Hamidi et al. [36, 37]. The required energy is given by the following equation:

$$
E=C \times\left(E_{\text {cement }}^{\text {process }}+E_{\text {cement }}^{\text {grinding }}\right)+G \times\left(\left(E_{\mathrm{GGBS}}^{\text {grinding }}+E_{\mathrm{GGBS}}^{\text {process }}\right),\right.
$$

$$
E_{\text {performance }}=\frac{E}{f_{\mathrm{cm}}},
$$

where $E$ is the energy consumption for producing $1 \mathrm{t}$ binder $(\mathrm{kWh} / \mathrm{t}) ; C$ and $G$ are the mass contents of cement and GGBS, respectively; $E_{\text {cement }}^{\text {process }}$ and $E_{\text {cement }}^{\text {grinding }}$ are the energy consumptions of the production process and the grinding of cement, respectively $(\mathrm{kWh} / \mathrm{t}) ; E_{\mathrm{GGBS}}^{\text {grinding }}$ is the energy consumption of the grinding of GGBS (kWh/t); $E_{\text {performance }}$ is the energy consumption for producing $1 \mathrm{t}$ binder, relative to the $28 \mathrm{~d}$ compressive strength of mortar $s((\mathrm{kWh} / \mathrm{t}) / \mathrm{MPa})$; and $f_{\mathrm{cm}}$ is the $28 \mathrm{~d}$ compressive strength of mortar. In the case of that, GGBS is a by-product of the steel production, and no energy is specially needed for its production. Therefore, the value of $E_{\mathrm{GGBS}}^{\text {process }}$ is zero.

\section{Results and Discussion}

3.1. Properties of Fresh Mixtures. Table 3 presents the setting times and densities of fresh mixtures. In general, both the initial and final setting times of pastes are found to be prolonged with increased contents of GGBS. The substitutions of $70 \%$ to $90 \%$ cement by GGBS resulted in increased initial and final setting times by times of 1.09 to 1.31 and 1.12 to 1.68 , respectively. This is more prominent in C20T23W55 but vanishes in C20T23W35, in which the initial and final setting times are $39 \mathrm{~min}$ and $6 \mathrm{~min}$ less than that of Con. Moreover, elevated curing temperatures accelerated significantly the set of paste. For example, the initial and final setting times of C20T40W45 are about half that of C20T23W45. In addition, the densities of GGBS-incorporating groups are lower than that of Con as a result of the lower density of GGBS than cement, as shown in Table 1.

3.2. Hydration Products of Pastes Analyzed by XRD. XRD analysis was conducted to investigate the crystalline compositions of $3 \mathrm{~d}$ and $28 \mathrm{~d}$ pastes, as presented in Figures 2 and 3 , respectively. A total of ten substance, i.e., $\mathrm{CH}$ $\left(\mathrm{Ca}(\mathrm{OH})_{2}\right)$, calcite, $\mathrm{C}_{4} \mathrm{AH}_{13}, \mathrm{C}_{3} \mathrm{~S}, \mathrm{C}_{2} \mathrm{~S}, \mathrm{CSH}(\mathrm{I})$, gehlenite, quartz, hydrotalite, and AFt (ettringite), were identified out as marked in the figures according to their JCDP files.

Figure 2(a) shows the XRD patterns of $3 \mathrm{~d}$ pastes incorporating $0 \%$ or $70 \%$ to $90 \%$ GGBS cured at $23^{\circ} \mathrm{C}$ with the fixed $w / b=0.45$. Among the ten identified substance, hydrocalumite with the characteristic peak at $2 \theta=10.8^{\circ}$ and gehlenite with the characteristic peak at $2 \theta=30.9^{\circ}$ were only found in the GGBS-incorporating pastes other than Con. These new crystals are thus speculated as a result of the activation reaction of GGBS by the free $\mathrm{CH}$ released from cement hydration. In fact, the hydration of cement-GGBS cementitious system primarily involves two associated hydration processes, which are the self-hydration of cement and the activation of GGBS by alkalis, i.e., $\mathrm{CH}[7,11]$. The activation reaction of GGBS is highly depended on the released $\mathrm{CH}$ by the self-hydration of cement in both the content and the formation rate [19]. The quantity of $\mathrm{CH}$ within paste is a critical indicator to understand the underlying hydration mechanism. Figure 2 (a) reveals that the characteristic peak heights of $\mathrm{CH}$ at $2 \theta=18^{\circ}$ and $33^{\circ}$ increase in a saltatory tendency with the increasing contents of cement from $10 \%$ to $30 \%$. Tiny peaks of $\mathrm{CH}$ were detected in C15T23W45 rather than in C10T23W45. This may indicate that the released $\mathrm{CH}$ was consumed almost completely by the activation reaction of GGBS. This, on the one hand, confirms the dilution effect of cement by GGBS leading to less $\mathrm{CH}$ production and, on the other hand, suggests an initial equilibrium between the demand of GGBS for the activation reaction and the supply of $\mathrm{CH}$ by the cement hydration at early age. $15 \%$ cement is sufficient to provide the required $\mathrm{CH}$ for $85 \%$ GGBS at $3 \mathrm{~d}$.

Figure 2(b) presents the XRD patterns of $3 \mathrm{~d}$ pastes considering the variables curing temperature and $w / b$. As for curing temperature, the characteristic peak heights of $\mathrm{CH}$ within pastes located at $2 \theta=18^{\circ}$ and $33^{\circ}$ firstly increase from $23^{\circ} \mathrm{C}$ to $40^{\circ} \mathrm{C}$ but then decrease or even tend to disappear from $40^{\circ} \mathrm{C}$ to $60^{\circ} \mathrm{C}$. This may be the competitive result of both the enhanced self-hydration of cement and activation of GGBS by elevated curing temperatures. From $40^{\circ} \mathrm{C}$ to $60^{\circ} \mathrm{C}$, the activation reaction of GGBS seems to be far accelerated than that of the self-hydration of cement, leading to most $\mathrm{CH}$ consumption. In addition, the XRD patterns of C20T23W55, C20T23W45, and C20T23W35 display no distinct difference in this figure.

Figure 3(a) presents the XRD patterns of $28 \mathrm{~d}$ pastes with the content of cement as the variable. A similar tendency that the characteristic peak heights of $\mathrm{CH}$ increase gradually with the content of cement is found in Figure 2(a). The equilibrium proportion of the blend cement for sufficient activation of GGBS has shifted from $85 \%$ GGBS-15\% cement at $3 \mathrm{~d}$ to $90 \%$ GGBS-10\% cement at $28 \mathrm{~d}$ since C10T23W 45 has the lowest peak heights of $\mathrm{CH}$ at $2 \theta=18^{\circ}$ and $33^{\circ}$. Figure $3(\mathrm{~b})$ shows the XRD patterns of $28 \mathrm{~d}$ pastes prepared by different curing temperatures and $w / b$. It can be seen from this figure that the characteristic peaks of $\mathrm{CH}$ of C20T40W45 and C20T60W45 are lower than that of C20T23W45. This 
TABLE 3: Setting times and densities of fresh mixtures.

\begin{tabular}{lccc}
\hline & Initial setting $(\mathrm{min})$ & Final setting $(\mathrm{min})$ & Density of fresh paste $(\mathrm{g} / \mathrm{ml})$ \\
\hline Con & 323 & 414 & 2.138 \\
C10T23W45 & 424 & 696 & 2.082 \\
C15T23W45 & 405 & 650 & 2.133 \\
C20T23W45 & 383 & 575 & 2.114 \\
C25T23W45 & 400 & 608 & 2.111 \\
C30T23W45 & 353 & 465 & 2.127 \\
C20T40W45 & 242 & 313 & 2.114 \\
C20T60W45 & 125 & 163 & 2.114 \\
C20T23W55 & 611 & $>720$ & 2.006 \\
C20T23W35 & 284 & 408 & 2.175 \\
\hline
\end{tabular}

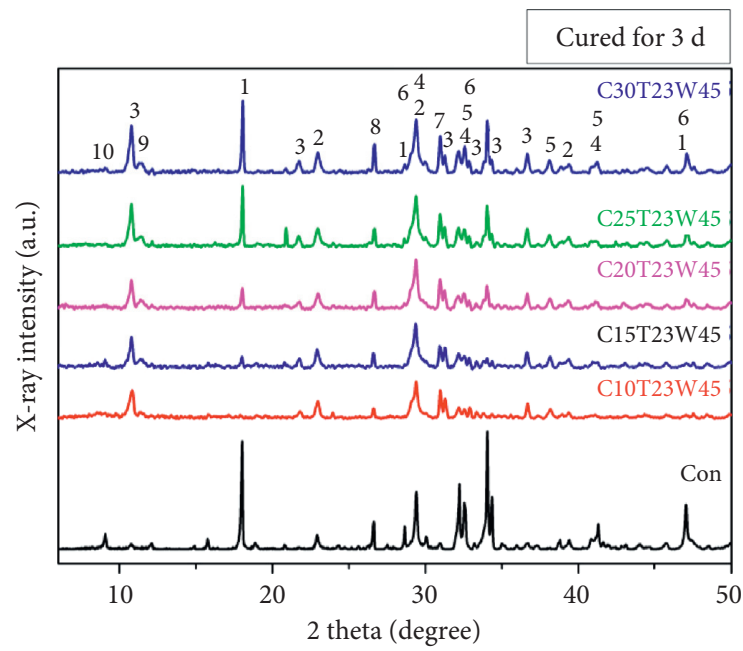

(a)

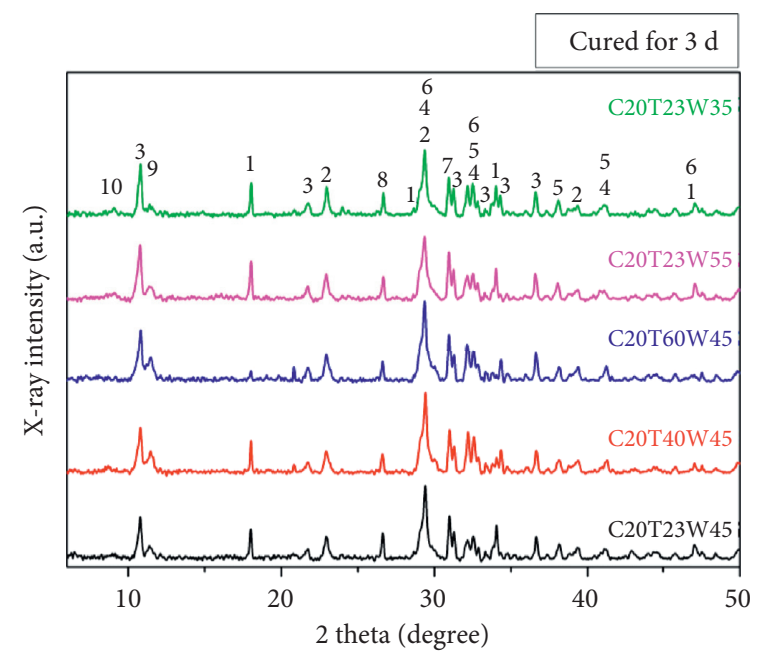

(b)

Figure 2: XRD patterns of $3 \mathrm{~d}$ pastes ((1) $\mathrm{CH},(2)$ calcite, (3) hydrocalumite, (4) $\mathrm{C}_{3} \mathrm{~S},(5) \mathrm{C}_{2} \mathrm{~S}$, (6) CSH (I), (7) gehlenite, (8) quartz, (9) hydrotalcite, and (10) AFt).

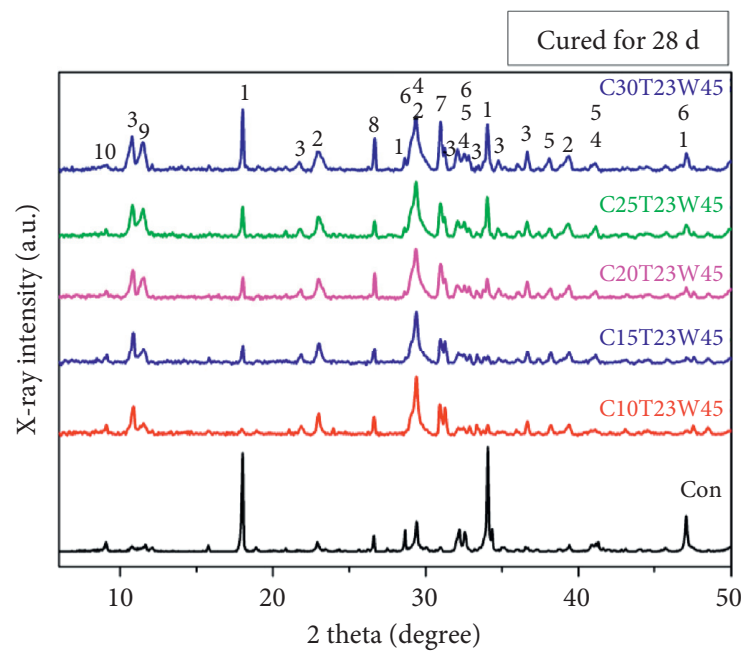

(a)

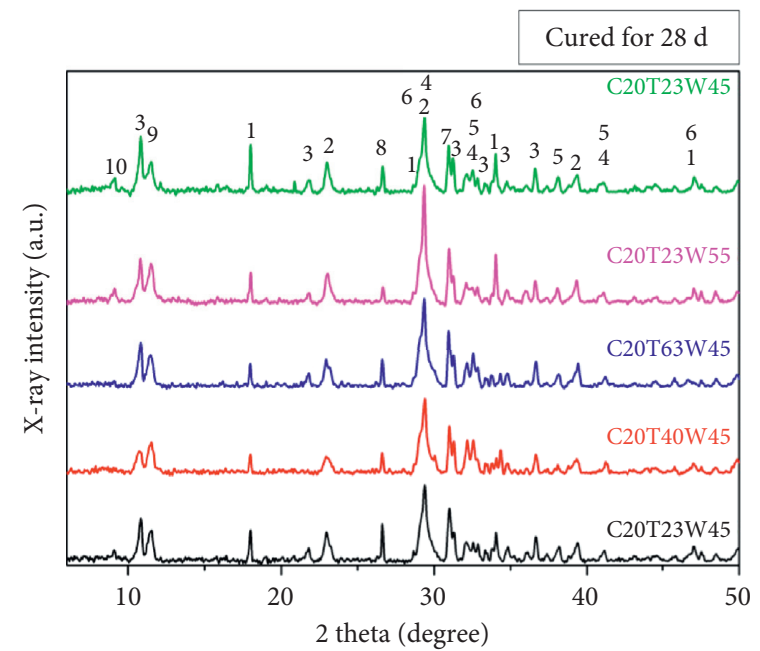

(b)

Figure 3: XRD patterns of $28 \mathrm{~d}$ pastes ((1) $\mathrm{CH}$, (2) calcite, (3) hydrocalumite, (4) $\mathrm{C}_{3} \mathrm{~S},(5) \mathrm{C}_{2} \mathrm{~S}$, (6) CSH (I), (7) gehlenite, (8) quartz, (9) hydrotalcite, and (10) AFt). 


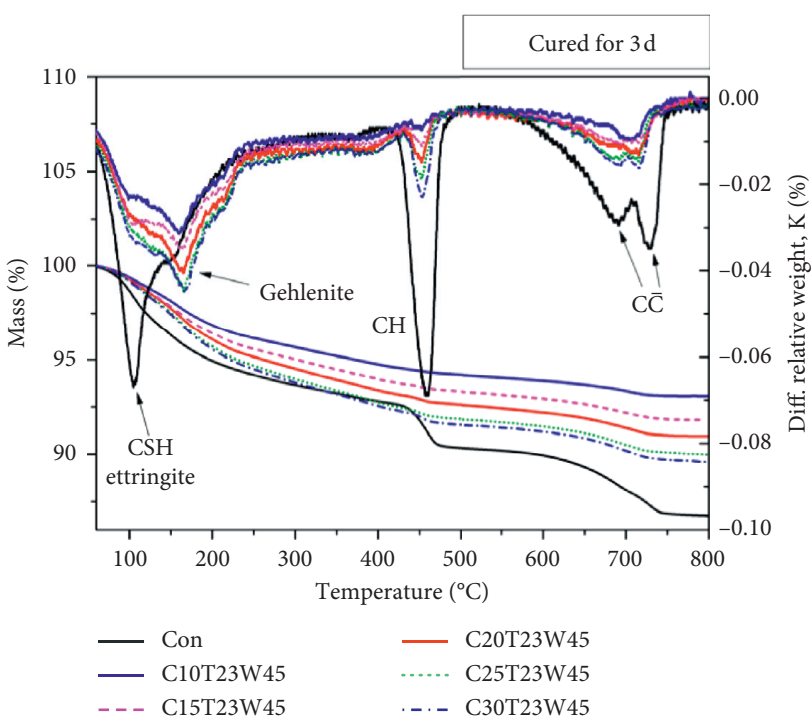

(a)

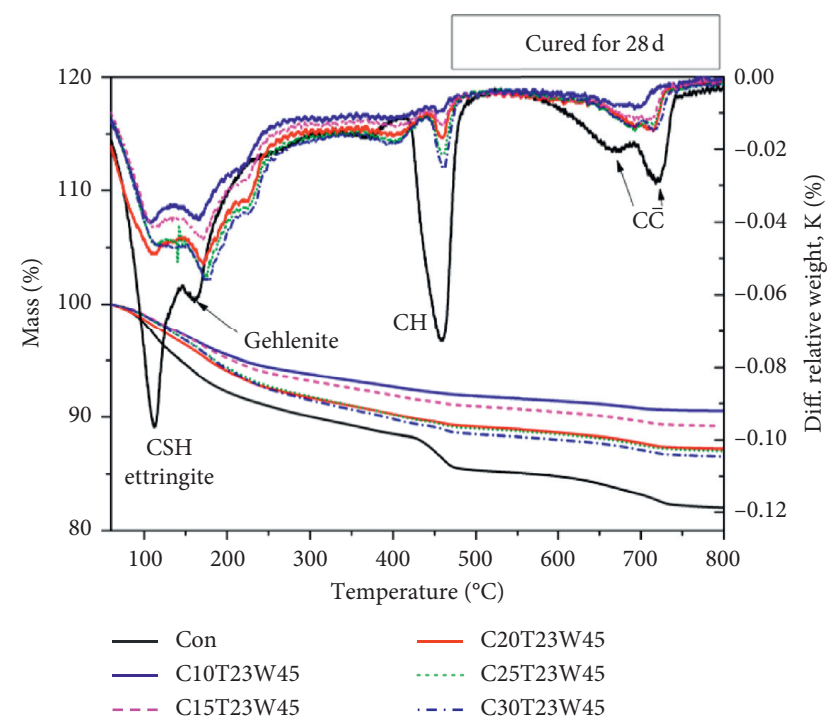

(b)

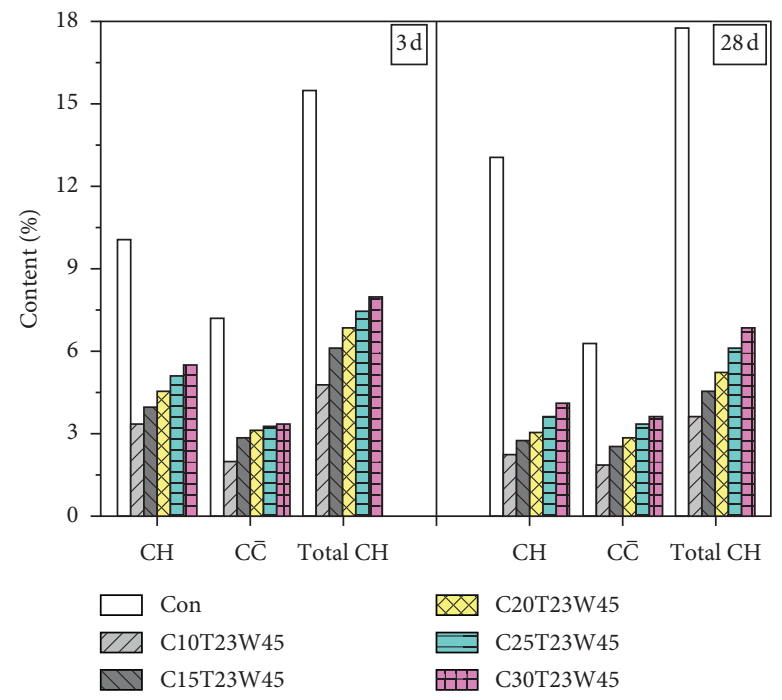

(c)

FIGURE 4: Hydration products of pastes with different contents of cement: (a) TGA-DTG results of $3 \mathrm{~d}$ pastes; (b) TGA-DTG results of $28 \mathrm{~d}$ pastes; (c) calculated contents of $\mathrm{CH}$ or $\mathrm{CC}(-)$ or total $\mathrm{CH}$.

further confirms that the consumption rates of $\mathrm{CH}$ by the activation reaction with GGBS surpassed the formation rates of $\mathrm{CH}$ by the self-hydration of cement at elevated curing temperatures.

3.3. Quantitative Analysis of Hydration Products by TGADTG. Figures 4(a) and 5(b) present the TGA-DTG results of $3 \mathrm{~d}$ and $28 \mathrm{~d}$ pastes with cement content as the variable, respectively. Four major endothermic peaks were distinctly identified in these DTG curves as marked, which correspond to the dehydration of CSH as well as decomposition of ettringite and gehlenite ranging from $80^{\circ} \mathrm{C}$ to $200^{\circ} \mathrm{C}$, dehydroxylation of $\mathrm{CH}$ around $450^{\circ} \mathrm{C}$, and decarbonation of $\mathrm{CaCO}_{3}(\mathrm{CC}(-))$ crystals in amorphous or crystalline phases around $700^{\circ} \mathrm{C}$ [38-41]. In general, the endothermic peak heights or their enveloping areas are observed visually to increase when more cement was incorporated.

The amounts of $\mathrm{CH}$ and $\mathrm{CC}(-)$ were calculated based on the mass losses ranging from $400^{\circ} \mathrm{C}$ to $500^{\circ} \mathrm{C}$ for $\mathrm{CH}$ and $600^{\circ} \mathrm{C}$ to $800^{\circ} \mathrm{C}$ for $\mathrm{CC}(-)$, as presented in Figure $4(\mathrm{c})$. The formation of $\mathrm{CC}(-)$ was attributed to the carbonation of $\mathrm{CH}$ during the moisture curing. Therefore, the total $\mathrm{CH}$ encompasses the content of $\mathrm{CH}$ and the carbonated $\mathrm{CH}$ with the same stoichiometric mole to that of $\mathrm{CC}(-)$. For $3 \mathrm{~d}$ pastes, the amounts of $\mathrm{CH}$ or $\mathrm{CC}(-)$ or the total $\mathrm{CH}$ of these pastes are less than half of that of Con (i.e., $30 \%-50 \%$ for the total $\mathrm{CH}$ ). This is due to the dilution effect of cement by GGBS at early ages in particular. For $28 \mathrm{~d}$ pastes, the contents of $\mathrm{CH}$ and total $\mathrm{CH}$ of GGBS-incorporating groups are far lower than that of Con. For instance, the contents of total $\mathrm{CH}$ of these GGBS-containing groups are just 

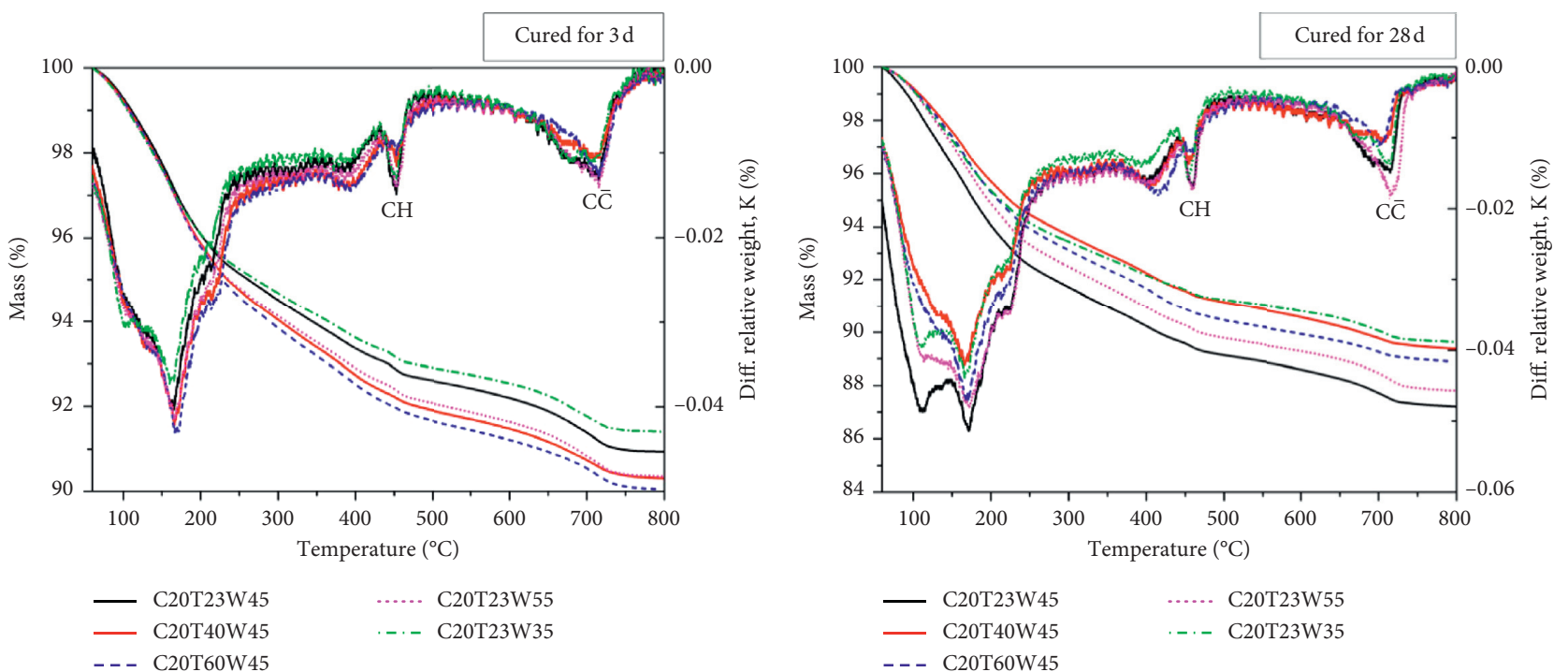

(a)

(b)

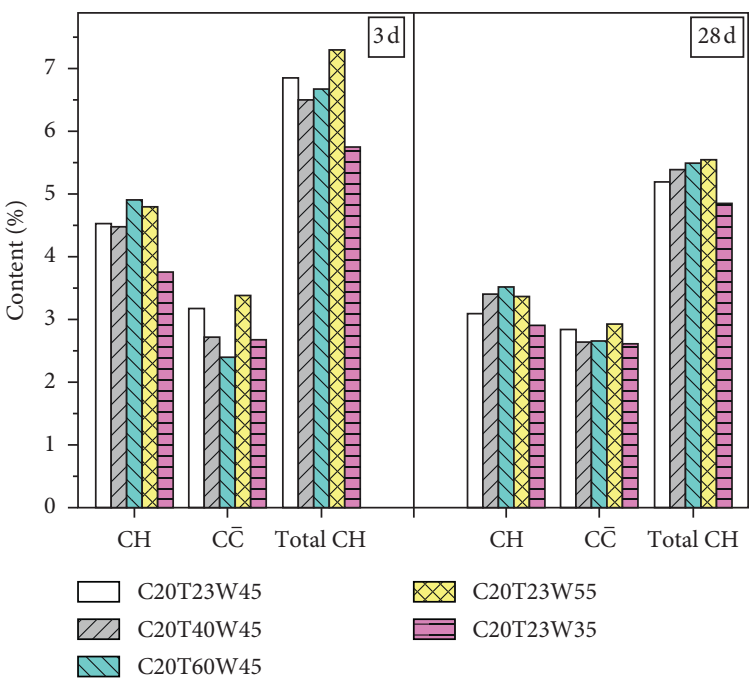

(c)

FIGURE 5: Hydration products of pastes prepared by different curing temperatures and $w / b$ : (a) TGA-DTG results of $3 \mathrm{~d}$ pastes; (b) TGADTG results of $28 \mathrm{~d}$ pastes; (c) calculated contents of $\mathrm{CH}$ or $\mathrm{CC}(-)$ or total $\mathrm{CH}$.

$15 \%-25 \%$ of that of Con. This decreased $\mathrm{CH}$ and total $\mathrm{CH}$ from $3 \mathrm{~d}$ to $28 \mathrm{~d}$ reveals the consumption of $\mathrm{CH}$ by GGBS.

Figures 5(a) and 5(b) show the TGA-DTG curves of $3 \mathrm{~d}$ and $28 \mathrm{~d}$ pastes prepared by different curing temperatures and $w / b$. The endothermic peaks of DTG curves are similar to that in Figure 4. In general, the contents of $\mathrm{CH}$ and total $\mathrm{CH}$ of pastes increase, and the content of $\mathrm{CC}(-)$ decreases with increasing curing temperatures, as further studied in Figure 5(c). This confirms that elevated curing temperatures were beneficial for the improvement of cement hydration, contributing to the generation of more hydration products. The amounts of $\mathrm{CH}$ or total $\mathrm{CH}$ of pastes with different $w / b$ values decrease with the decreasing $w / b$ at $3 \mathrm{~d}$ and $28 \mathrm{~d}$. Since the contents of cement in pastes with lower $w / b$ were actually higher as less water was used, it is indicated that lower w/b promoted the consumption rates of $\mathrm{CH}$.
3.4. Compressive Strength. Figure 6(a) presents the compressive strength of mortars with different contents of cement. In general, the compressive strength of these mortars increases with increasing contents of cement at three ages. The early-age compressive strengths of GGBS-incorporating mortars are markedly lower than that of Con and are 30\%$50 \%$ at $3 \mathrm{~d}$ and $40 \%-79 \%$ at $7 \mathrm{~d}$ of Con, respectively. Nevertheless, the $28 \mathrm{~d}$ compressive strengths of those GGBSincorporating mortars developed much quickly, and the values of C25T23W45 and C30T23W45 are 90.7\% and $95.3 \%$ of that of Con. The subsequent increments of the compressive strengths of GGBS-incorporating mortars are primarily attributed to the activation reaction of GGBS with the free $\mathrm{CH}$. Through this activation reaction, supplementary stress-bearing C-S-H can be generated $[7,10]$. This also implies important achievement that one can replace $75 \%$ or 


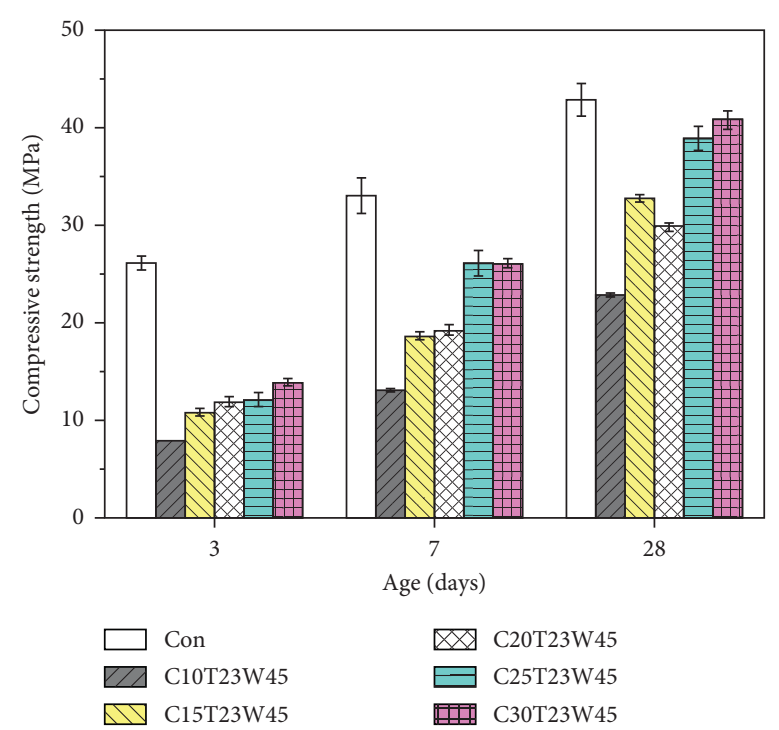

(a)

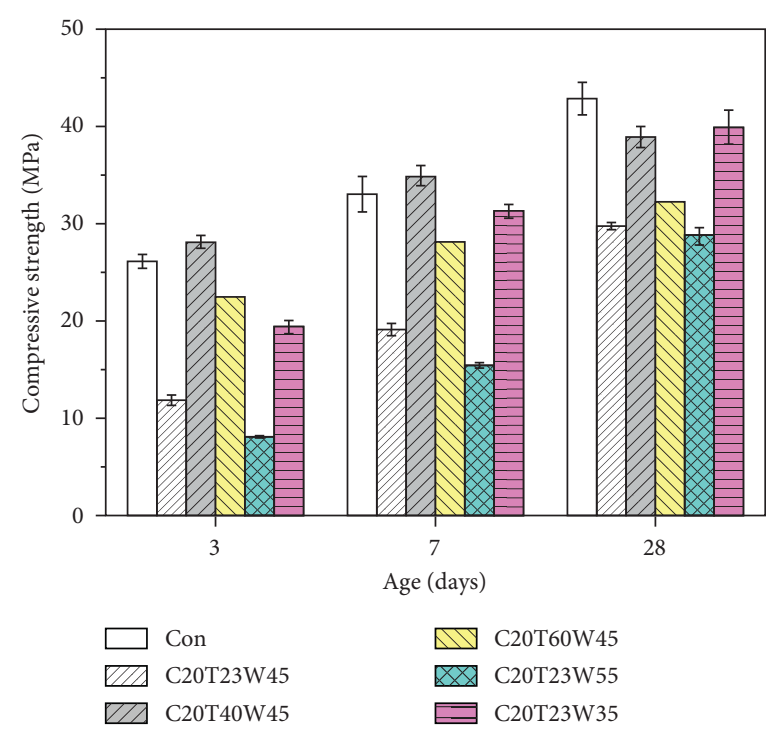

(b)

FIGURE 6: Compressive strength of mortars: (a) mortars with different contents of cement; (b) mortars prepared by different curing temperatures and $w / b$.

$70 \%$ cement by GGBS to prepare NSM with comparable longer compressive strength to that of mixtures prepared by cement only. Thanks to this, great benefits can be gained in terms of environment protection, cost reduction, waste utilization, as well as energy saving.

Figure 6(b) presents the compressive strength of mortars prepared by different curing temperatures and $w / b$. It can be found that $40^{\circ} \mathrm{C}$ is the optimal curing temperature to achieve desired compressive strength. Compared to Con, the compressive strengths of C20T40W45 are higher by $7.8 \%$ at $3 \mathrm{~d}$ and $5.9 \%$ at $7 \mathrm{~d}$ than that of Con. The $28 \mathrm{~d}$ compressive strength of C20T40W45 is lower but still gained $91 \%$ of that of Con at $39.0 \mathrm{MPa}$. From the point of chemical reaction, curing temperature is one of the methods to facilitate the dissolution of GGBS and cement and crystallization of hydration products. However, too high temperatures may cause degraded properties of the hydration products as well as the mechanical strength, i.e., $60^{\circ} \mathrm{C}$. Another method to gain desired compressive strength is well adopted reducing the $w / b$. As can be seen from this figure, the compressive strength normally increases with decreased $w / b$ mainly due to formation of a denser microstructure. The compressive strengths of C20T23W35 are $74.2 \%$ at $3 \mathrm{~d}, 95.2 \%$ at $7 \mathrm{~d}$, and $93.2 \%$ at $28 \mathrm{~d}$ of that of Con.

3.5. Microstructure Observation by SEM. The microstructure evolution of GGBS-incorporating mortars was examined by SEM, as shown in Figure 7. Figure 7(a) presents the SEM image of $3 \mathrm{~d}$ C10T23W 45 mortar. It displays a much porous microstructure constituted by adhesive particles and tiny schistose crystals that most possibly are $\mathrm{CH}$. In the case of that $90 \%$ of the binder is GGBS, the particles are GGBS that have reacted with the released $\mathrm{CH}$, nevertheless with low reaction degree. When incorporating $20 \%$ cement into the mortar (Figure 7(c)), a larger porous matrix formed instead of part of the adhesive particles, as observed in Figure 7(a). More prominently, as shown in Figure 7(e), the morphology of the $3 \mathrm{~d}$ C30T23W45 mortar is much denser as irregular particles are bonded compactly by porous binders as further observed from the inset in this figure. The differences in the $3 \mathrm{~d}$ morphology among these mortars vanished at $28 \mathrm{~d}$ as they display a similar microstructure. As presented in Figures $7(\mathrm{~b}), 7(\mathrm{~d})$, and $7(\mathrm{f})$, a dense matrix formed in the three samples despite the contents of GGBS varying from $70 \%$ to $90 \%$. This confirms that a longer curing duration has transformed GGBS into the binder that structured the dense stress-bearing matrix.

Figure 7(g) shows the SEM images of $3 \mathrm{~d}$ C20T40W45 mortar. Large dense matrix and fine particles are found, and ribbon-like $\mathrm{CSH}$ formed. This figure is much different from that of C20T23W45 with the same proportion but lower curing temperature at $23^{\circ} \mathrm{C}$. This confirms the role of a higher curing temperature in enhancing both the self-hydration of cement and activation reaction of GGBS by $\mathrm{CH}$. Figure $7(\mathrm{~h})$ presents the SEM image of $28 \mathrm{~d}$ C20T40W45 mortar. The noteworthy feature of this figure is the existence of fibrous CSH intertwining together. Figure 7(i) presents the SEM images of $3 \mathrm{~d}$ C20T23W35. It displays a porous morphology and nevertheless is still denser than that of C20T23W45, as proved in Figure 7(j). This is one of the reasons for the higher compressive strength of mortars with a lower $w / b$.

3.6. Microstructure Analysis by MIP. The pore structures of representative mortars were studied by MIP, as presented in Figure 8 . The pore sizes of all mortars primarily distribute within two zones: ZI $(>50 \mu \mathrm{m})$ and ZII $(<100 \mathrm{~nm})$. The former commonly suggests the existence of voids or gas inclusion. Within ZI, the pore volume of Con is the lowest while that of GGBS-incorporating mortars cured under $23^{\circ} \mathrm{C}$ 

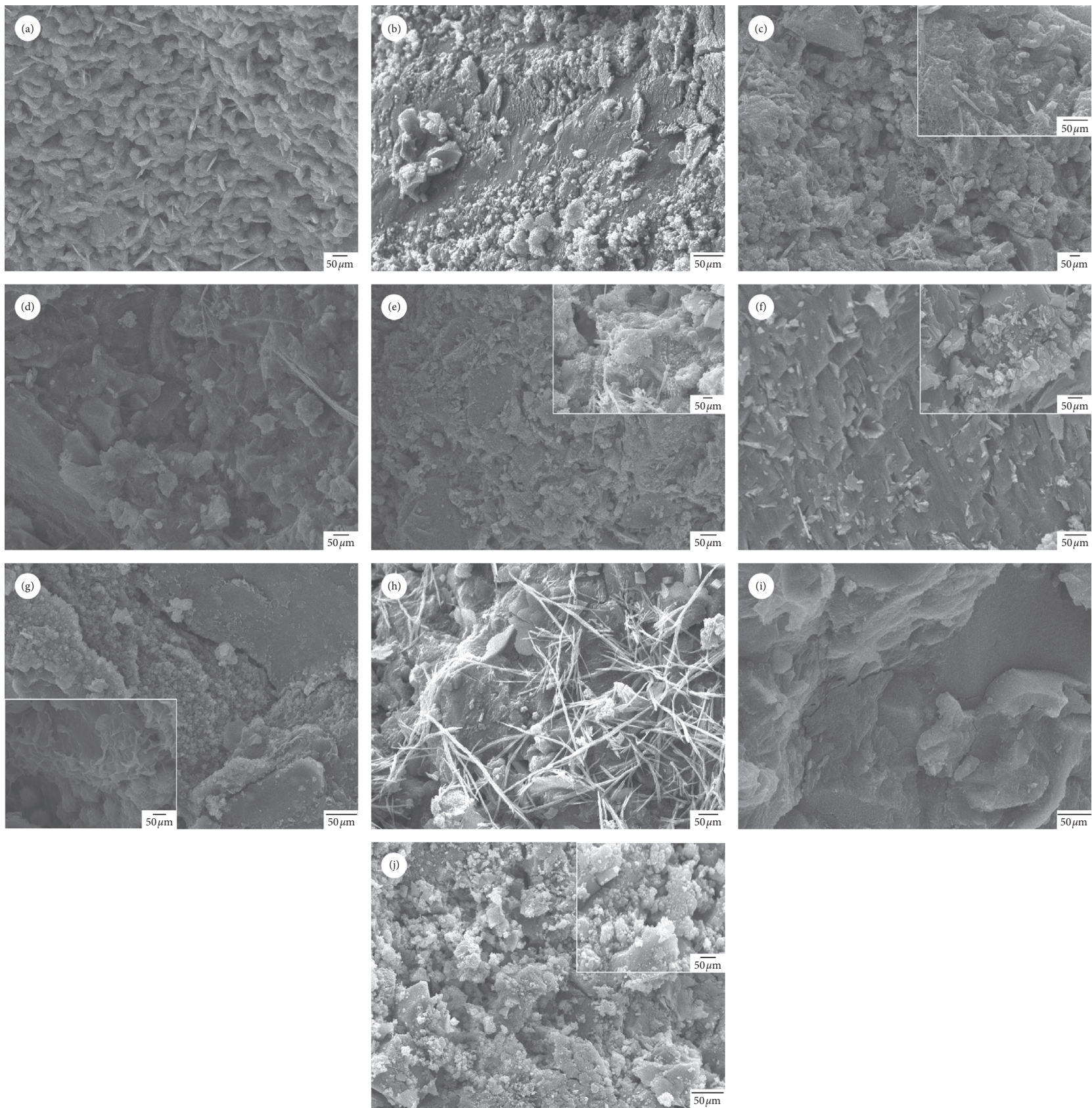

FIGURE 7: SEM images of partial GGBS-incorporating $3 \mathrm{~d}$ and $28 \mathrm{~d}$ mortars: (a) $3 \mathrm{~d}$ C10T23W45; (b) $28 \mathrm{~d}$ C10T23W45; (c) $3 \mathrm{~d}$ C20T23W45; (d) $28 \mathrm{~d}$ C20T23W45; (e) $3 \mathrm{~d}$ C30T23W45; (f) $28 \mathrm{~d}$ C30T23W45; (g) 3d C20T40W45; (h) 28d C20T40W45; (i) 3d C20T23W35; (j) 28 d C20T23W35.

are much higher. Within ZII, the pore sizes of GGBS-incorporating groups are finer than that of Con. It can be seen that the pore sizes of Con mainly concentrate around $50 \mathrm{~nm}$ as a peak. When $90 \%$ GGBS and $10 \%$ cement were blended, two peaks of pore sizes appear in C10T23W45. The first one is higher but shifts left to the sole peak of Con. The second intense peak of pore sizes formed around $10 \mathrm{~nm}$, as further expounded by the inset. When blending more cement in mortars, the first peak of pore sizes observed in C10T23W45 disappears in C20T23W45 and C30T23W45, and consequently, broader peaks of pore sizes formed. This suggests that the incorporation of GGBS into NSM results in promoted porosity but refined pore sizes. The formation of the binding system in these mortars incorporating GGBS as the major cementing material highly depended on the activation reaction of GGBS with the free $\mathrm{CH}$. The activation reaction generated hydration products which filled the voids or pores within the microstructure of mortars. Nevertheless, the produced hydration products among these GGBS-incorporating mortars are less than that of Con, as calculated in Figures 4 and 5, leading to less pores being occupied or filled.

Elevated curing temperatures or low $w / b$ are also helpful to refine the pore sizes of GGBS-incorporating mortars. The 


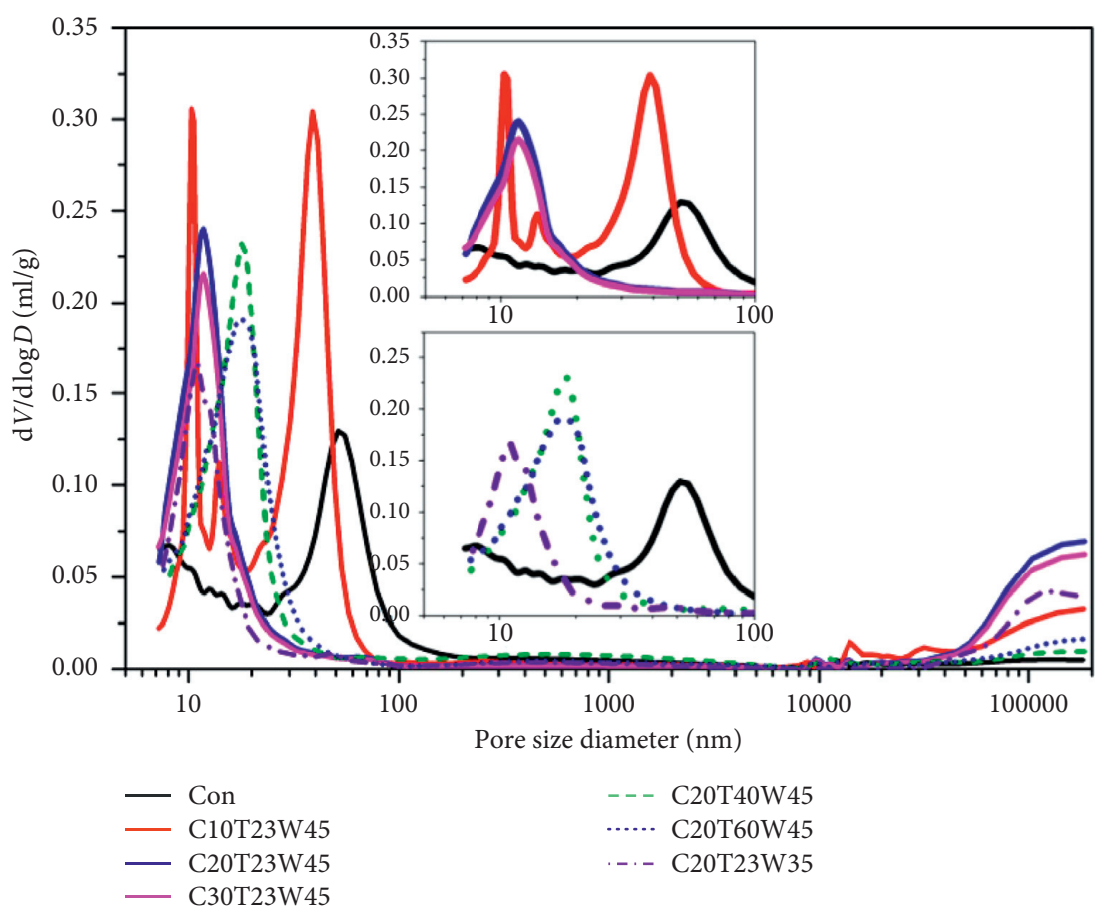

Figure 8: Pore sizes of representative $28 \mathrm{~d}$ mortars.

major difference between the two compressive strength compensation methods on the pore sizes is that elevated curing temperatures increase the refined pore sizes from $10 \mathrm{~nm}$ to $20 \mathrm{~nm}$ within ZII and nevertheless decrease the pore volumes within ZI, as found in Figure 8 and the inset. Figure 9 presents the calculated cumulative pore volume based on Figure 8 . This figure clearly confirms that the incorporation of GGBS promoted the pore volumes of NSM as the ultimate cumulative pore volume of Con is the lowest. Nevertheless, the pore sizes of GGBS-incorporating groups are finer than that of Con since most ascending curves of GGBS-incorporating groups shift left to that of Con. This refinement in pore sizes is beneficial to improve the durability performance of NSM with respect to external environmental actions, i.e., chloride migration and sulfate attack [16].

3.7. Ecoefficiency Evaluation of the Binary Cement. The energy consumption for producing and grinding $1 \mathrm{t}$ cement has been reported as $E_{\text {cement }}^{\text {process }}=1039 \mathrm{kWh} / \mathrm{t} \quad$ [42] and $E_{\text {cement }}^{\text {grinding }}=50 \mathrm{kWh} / \mathrm{t}$ [37]. According to DB31 581 [43], a comprehensive electricity consumption of GGBS encompasses the whole production process of GGBS, i.e., raw material conveying, drying, grinding, powder separating, product storage and delivering, and the supporting processes, i.e., electricity consumption for illumination and temperature control. It has been specified that the norm of comprehensive electricity consumption of GGBS should be less than $50 \mathrm{kWh} /$ $\mathrm{t}$. Therefore, the energy consumption for grinding $1 \mathrm{t}$ GGBS is determined as $E_{\mathrm{GGBS}}^{\text {grinding }}=50 \mathrm{kWh} / \mathrm{t}$ in this paper.

Figure 10 presents the calculated energy requirements of $1 \mathrm{t}$ binder $E$ and performance energy $E_{\text {performance. The }}$

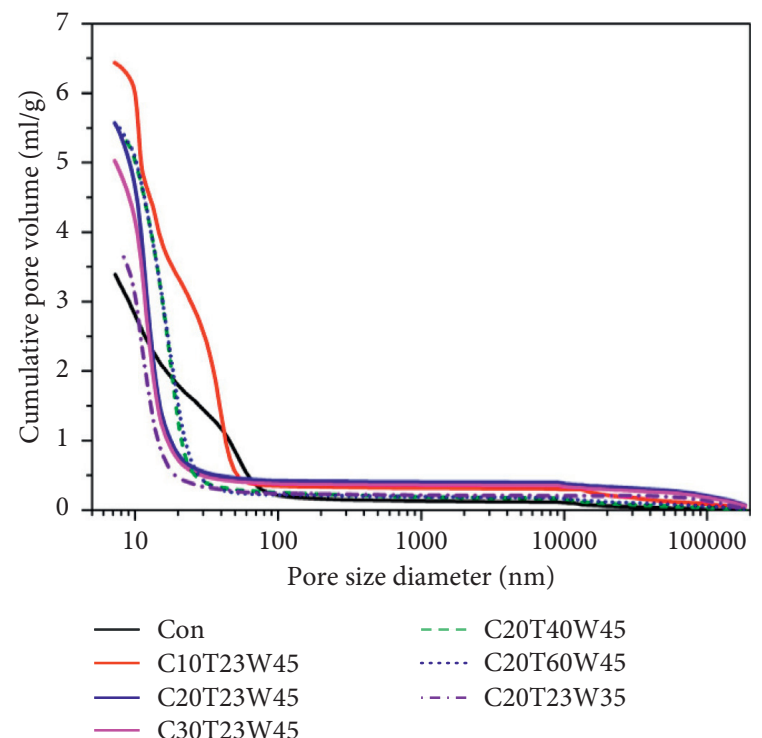

Figure 9: Cumulative pore sizes of representative $28 \mathrm{~d}$ mortars.

ecoefficiency of NSM incorporating high volume of GGBS is obvious. In general, incorporating $70 \%$ to $90 \%$ GGBS into binders contributes to decreased $E$ by $67 \%$ to $86 \%$ as well as lessened $E_{\text {performance }}$ by $65 \%$ to $75 \%$. Among the ten mixtures, the three lowest values of $E_{\text {performance }}$ are $6.28(\mathrm{kWh} / \mathrm{t}) /$ $\mathrm{MPa}(\mathrm{C} 15 \mathrm{~T} 23 \mathrm{~W} 45), 6.44(\mathrm{kWh} / \mathrm{t}) / \mathrm{MPa}(\mathrm{C} 20 \mathrm{~T} 23 \mathrm{~W} 35)$, and $6.61(\mathrm{kWh} / \mathrm{t}) / \mathrm{MPa}(\mathrm{C} 20 \mathrm{~T} 40 \mathrm{~W} 45)$. From the point of performance energy, it is thus suggested to replace $80 \%$ to $85 \%$ cement by GGBS to gain optimal ecoefficiency. Low $w / b$ and high curing temperature at $40^{\circ} \mathrm{C}$ are effective methods to gain a lower $E_{\text {performance. }}$. Therefore, the ecological upgrade of 


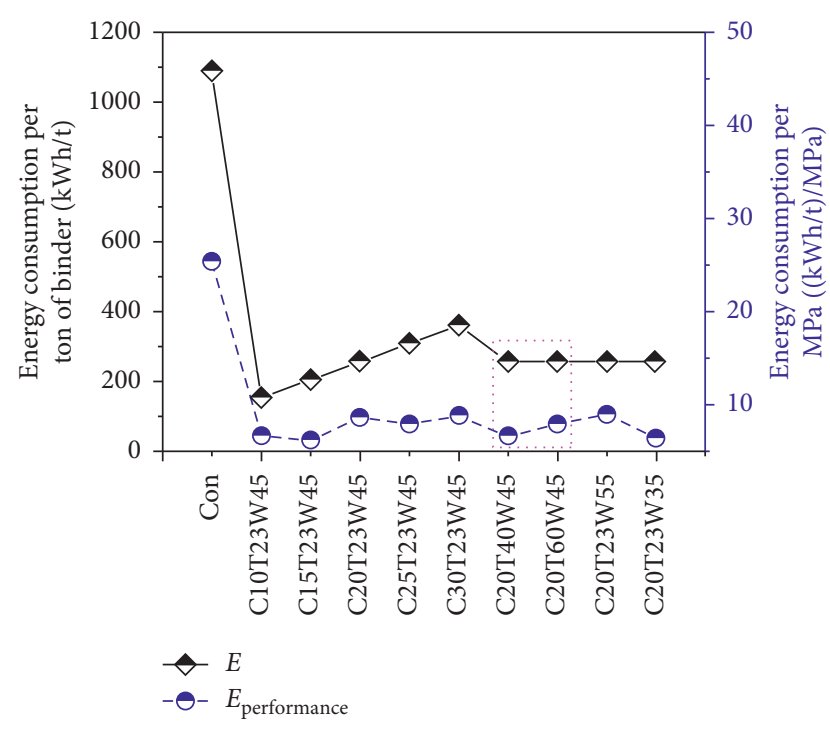

FIGURE 10: Ecoefficiency evaluation of mortars with and without GGBS.

NSM by using high volume of GGBS provides a better choice for the sustainable development in a greener way. It should be noted that the calculation of $E_{\text {performance }}$ of C20T40W45 and C20T60W45 did not involve the extra energy for high temperature curing; thus, the ecoefficiency was underestimated from a practical point.

\section{Conclusions}

This paper has evaluated the feasibility of ecological upgrade of NSM by using high volume of GGBS (70\%-90\%). The following conclusions can be drawn based on the experimental results:

(i) Ecological upgrade of NSM is viable and obvious by substituting $70 \%$ to $90 \%$ cement by GGBS. Accordingly, the energy requirements of $1 \mathrm{t}$ binder can be saved by $67 \%$ to $86 \%$, and the performance energy can be reduced from $25.4(\mathrm{kWh} / \mathrm{t}) / \mathrm{MPa}$ to 6 to $8(\mathrm{kWh} / \mathrm{t}) / \mathrm{MPa}$.

(ii) The setting times of pastes were prolonged with increased GGBS. The substitution of $70 \%$ to $90 \%$ cement by GGBS resulted in increased initial and final setting times by times of 1.09 to 1.31 and 1.12 to 1.68 , respectively.

(iii) NSM with proper contents of GGBS can develop acceptable $28 \mathrm{~d}$ compressive strengths than that of the control group. The early-age compressive strengths of GGBS-incorporating NSM were far lower but can be mitigated by methods of evaluated temperature curing or decreasing $w / b$.

(iv) The incorporation of high volume of GGBS increased the porosities but refined the pore structures of mortars. Mortars with GGBS displayed very porous microstructures at $3 \mathrm{~d}$ with visible bonded GGBS particles. Nevertheless, raising the curing temperature to $40^{\circ} \mathrm{C}$ or decreasing $w / b$ at 0.35 helped dense the microstructures. At $28 \mathrm{~d}$, all mortars displayed a similar morphology consisted by a dense matrix. Moreover, the pore sizes of mortars were significantly refined by incorporating GGBS.

\section{Data Availability}

The data used to support the findings of this study are available from the corresponding author upon request.

\section{Conflicts of Interest}

The authors declare that they have no conflicts of interest.

\section{Acknowledgments}

This work was supported by the China Postdoctoral Science Foundation (no. 2018M632518), Anhui Postdoctoral Science Foundation (nos. 2017B150 and 2018B248), Natural Science Foundation of Anhui University (KJ2018A0074), Key Research and Development Program Project of Anhui Province (201904a07020081), Nature Science Foundation of Anhui (1908085QE213), and Huainan Science and Technology Planning Project (2018A363).

\section{References}

[1] D. Xu, Y. Cui, H. Li, K. Yang, W. Xu, and Y. Chen, "On the future of Chinese cement industry," Cement and Concrete Research, vol. 78, pp. 2-13, 2015.

[2] P. Chen, J. Wang, L. Wang, and Y. Xu, "Perforated cenospheres: a reactive internal curing agent for alkali activated slag mortars," Cement and Concrete Composites, vol. 104, Article ID 103351, 2019.

[3] P. Chen, J. Wang, L. Wang, Y. Xu, X. Qian, and H. Ma, "Producing vaterite by $\mathrm{CO}_{2}$ sequestration in the waste solution of chemical treatment of recycled concrete aggregates," Journal of Cleaner Production, vol. 149, pp. 735-742, 2017.

[4] H. E. H. Seleem, A. M. Rashad, and T. Elsokary, "Effect of elevated temperature on physico-mechanical properties of blended cement concrete," Construction and Building Materials, vol. 25, no. 2, pp. 1009-1017, 2011.

[5] R. Siddique and R. Bennacer, "Use of iron and steel industry by-product (GGBS) in cement paste and mortar," Resources, Conservation and Recycling, vol. 69, no. 12, pp. 29-34, 2012.

[6] R. Dhirhi, K. Prasad, A. K. Shukla et al., "Experimental study of rotating dry slag granulation unit: operating regimes, particle size analysis and scale up," Applied Thermal Engineering, vol. 107, pp. 898-906, 2016.

[7] X. Fu, W. Hou, C. Yang, D. Li, and X. Wu, "Studies on Portland cement with large amount of slag," Cement and Concrete Research, vol. 30, no. 4, pp. 645-649, 2000.

[8] K. Ganesh Babu and V. Sree Rama Kumar, "Efficiency of GGBS in concrete," Cement and Concrete Research, vol. 30, no. 7, pp. 1031-1036, 2000.

[9] Z. Lin, Slag Based Series Eco-Cement, China Building Materials Industry Press, Beijing, China, 2018. 
[10] E. Özbay, M. Erdemir, and H. İ. Durmuş, "Utilization and efficiency of ground granulated blast furnace slag on concrete properties-a review," Construction and Building Materials, vol. 105, pp. 423-434, 2016.

[11] C. Shi and J. Qian, "High performance cementing materials from industrial slags-a review," Resources, Conservation and Recycling, vol. 29, no. 3, pp. 195-207, 2000.

[12] M. S. Nasr, A. A. Shubbar, Z. A.-A. R. Abed, and M. S. Ibrahim, "Properties of eco-friendly cement mortar contained recycled materials from different sources," Journal of Building Engineering, vol. 31, Article ID 101444, 2020.

[13] A. A. Shubbar, M. Sadique, P. Kot, and W. Atherton, "Future of clay-based construction materials-a review," Construction and Building Materials, vol. 210, pp. 172-187, 2019.

[14] A. M. Rashad, "An investigation on very high volume slag pastes subjected to elevated temperatures," Construction and Building Materials, vol. 74, pp. 249-258, 2015.

[15] P. A. M. Basheer, P. R. V. Gilleece, A. E. Long, and W. J. Mc Carter, "Monitoring electrical resistance of concretes containing alternative cementitious materials to assess their resistance to chloride penetration," Cement and Concrete Composites, vol. 24, no. 5, pp. 437-449, 2002.

[16] K. Li, Q. Zeng, M. Luo, and X. Pang, "Effect of self-desiccation on the pore structure of paste and mortar incorporating $70 \%$ GGBS," Construction and Building Materials, vol. 51, pp. 329-337, 2014.

[17] F. F. Ataie, M. C. G. Juenger, S. C. Taylor-Lange, and K. A. Riding, "Comparison of the retarding mechanisms of zinc oxide and sucrose on cement hydration and interactions with supplementary cementitious materials," Cement and Concrete Research, vol. 72, pp. 128-136, 2015.

[18] H. F. W. Taylor, Cement Chemistry, Thomas Telford Publishing, London, UK, 1997.

[19] J. M. Gao, C. X. Qian, H. F. Liu, B. Wang, and L. Li, "ITZ microstructure of concrete containing GGBS," Cement and Concrete Research, vol. 35, no. 7, pp. 1299-1304, 2005.

[20] M.-H. Zhang, J. Islam, and S. Peethamparan, "Use of nanosilica to increase early strength and reduce setting time of concretes with high volumes of slag," Cement and Concrete Composites, vol. 34, no. 5, pp. 650-662, 2012.

[21] A. A. Shubbar, H. Jafer, M. Abdulredha et al., "Properties of cement mortar incorporated high volume fraction of GGBFS and CKD from 1 day to 550 days," Journal of Building Engineering, vol. 30, Article ID 101327, 2020.

[22] A. A. Shubbar, H. Jafer, A. Dulaimi, K. Hashim, W. Atherton, and M. Sadique, "The development of a low carbon binder produced from the ternary blending of cement, ground granulated blast furnace slag and high calcium fly ash: an experimental and statistical approach," Construction and Building Materials, vol. 187, pp. 1051-1060, 2018.

[23] R. Siddique and M. I. Khan, Supplementary Cementing Materials, Springer Berlin Heidelberg, Heidelberg, Germany, 2011.

[24] F. Sajedi, "Mechanical activation of cement-slag mortars," Construction and Building Materials, vol. 26, no. 1, pp. 41-48, 2012.

[25] M. A. Megat Johari, J. J. Brooks, S. Kabir, and P. Rivard, "Influence of supplementary cementitious materials on engineering properties of high strength concrete," Construction and Building Materials, vol. 25, no. 5, pp. 2639-2648, 2011.

[26] A. M. Rashad and D. M. Sadek, "An investigation on Portland cement replaced by high-volume GGBS pastes modified with micro-sized metakaolin subjected to elevated temperatures,"
International Journal of Sustainable Built Environment, vol. 6, no. 1, pp. 91-101, 2016.

[27] A. Alhozaimy, A. Al-Negheimish, O. A. Alawad, M. S. Jaafar, and J. Noorzaei, "Binary and ternary effects of ground dune sand and blast furnace slag on the compressive strength of mortar," Cement and Concrete Composites, vol. 34, no. 6, pp. 734-738, 2012.

[28] C. Jiang, Y. Yang, Y. Wang, Y. Zhou, and C. Ma, “Autogenous shrinkage of high performance concrete containing mineral admixtures under different curing temperatures," Construction and Building Materials, vol. 61, no. 3, pp. 260-269, 2014.

[29] F. Sajedi and H. A. Razak, "Effects of thermal and mechanical activation methods on compressive strength of ordinary Portland cement-slag mortar," Materials \& Design, vol. 32, no. 2, pp. 984-995, 2011.

[30] M.-H. Zhang and J. Islam, "Use of nano-silica to reduce setting time and increase early strength of concretes with high volumes of fly ash or slag," Construction and Building Materials, vol. 29, pp. 573-580, 2012.

[31] A. Hosan and F. U. A. Shaikh, "Influence of nano- $\mathrm{CaCO}_{3}$ addition on the compressive strength and microstructure of high volume slag and high volume slag-fly ash blended pastes," Journal of Building Engineering, vol. 27, Article ID 100929, 2020.

[32] H. El-Chabib and A. Ibrahim, "The performance of highstrength flowable concrete made with binary, ternary, or quaternary binder in hot climate," Construction and Building Materials, vol. 47, no. 10, pp. 245-253, 2013.

[33] E. Güneyisi, M. Gesoğlu, and E. Özbay, "Strength and drying shrinkage properties of self-compacting concretes incorporating multi-system blended mineral admixtures," Construction and Building Materials, vol. 24, no. 10, pp. 1878-1887, 2010.

[34] JGJ/T 439, Technical Standard for Application of Alkali-Activated Slag Concrete, Ministry of Housing and Urban-Rural Development of the People's Republic of China, Beijing, China, 2018.

[35] ASTM C191, Standard Test Method for Time of Setting of Hydraulic Cement by Vicat Needle, ASTM International, West Conshohocken, PA, USA, 1999.

[36] J. M. Medina, I. F. Sáez del Bosque, M. Frías, M. I. Sánchez de Rojas, and C. Medina, "Design and properties of eco-friendly binary mortars containing ash from biomass-fuelled power plants," Cement and Concrete Composites, vol. 104, Article ID 103372, 2019.

[37] M. Hamidi, L. Kacimi, M. Cyr, and P. Clastres, "Evaluation and improvement of pozzolanic activity of andesite for its use in eco-efficient cement," Construction and Building Materials, vol. 47, pp. 1268-1277, 2013.

[38] X.-H. Yuan, W. Chen, Z.-A. Lu, and H. Chen, "Shrinkage compensation of alkali-activated slag concrete and microstructural analysis," Construction and Building Materials, vol. 66, pp. 422-428, 2014.

[39] A. Hanif, P. Parthasarathy, H. Ma, T. Fan, and Z. Li, "Properties improvement of fly ash cenosphere modified cement pastes using nano silica," Cement and Concrete Composites, vol. 81, pp. 35-48, 2017.

[40] X.-M. Kong, H. Liu, Z.-B. Lu, and D.-M. Wang, "The influence of silanes on hydration and strength development of cementitious systems," Cement and Concrete Research, vol. 67, no. 18, pp. 168-178, 2015.

[41] M. S. Morsy, S. H. Alsayed, and M. Aqel, "Effect of nano-clay on mechanical properties and microstructure of ordinary 
Portland cement mortar," International Journal of Civil and Environmental Engineering, vol. 10, no. 1, pp. 21-25, 2010.

[42] I. Arribas, I. Vegas, V. García, R. Vigil de la Villa, S. MartínezRamírez, and M. Frías, "The deterioration and environmental impact of binary cements containing thermally activated coal mining waste due to calcium leaching," Journal of Cleaner Production, vol. 183, pp. 887-897, 2018.

[43] DD 31/581, The Norm of Energy Consumption Per Unit Products for Ground Granulated Blast Furnace Slag, Shanghai Quality and Technical Supervision, Shanghai, China, 2012. 